\title{
0 (RE)AGIR DA ENFERMAGEM DIANTE DA PARADA CARDIOPULMONAR: UM DESAFIO NO COTIDIANO
}

\author{
The re (act) from front to stop nursing cardiopulmonary: a \\ challenge in the daily \\ La re (acto) de frente para detener la enfermería \\ cardiopulmonar: un reto en el diario
}

Thaís Duarte da Graça ${ }^{1}$

Glaucia Valente Valadares ${ }^{2}$

\section{RESUMO}

Esta pesquisa apresentou como objetivos: conhecer a vivência da equipe de enfermagem no processo do cuidado ao cliente em parada cardiopulmonar; relacionar nesta situação o conhecimento teórico com o conhecimento prático; discutir as possíveis implicações para o cuidado de enfermagem. Privilegiou-se a pesquisa de natureza qualitativa, tendo sido utilizados como instrumentos de coleta de dados: a entrevista semi-estruturada e a observação participante assistemática. Os atores sociais foram os profissionais da equipe de enfermagem que trabalham em um hospital público do Estado do Rio de Janeiro. 0 estudo baseou-se nas idéias de Valadares (2006), que discorre sobre o enfrentamento do conhecimento novo. Dos resultados, emergiram três categorias, sendo possível apreender que: as equipes de enfermagem (re) agem de maneira singular, dependendo do local em que trabalham; a experiência acumulada modifica as atitudes nesta situação; e existem fatores cotidianos que influenciam no cuidado de enfermagem prestado a esta clientela.

Palavras-chave: Parada cardiopulmonar. Cuidado de enfermagem. Equipe de enfermagem.

\begin{abstract}
This research showed the following objectives: to know the experience of the nursing staff in the process of care through customer stop in cardiopulmonary; relate at this situation, the theoretical with the practical knowledge; discuss the possible implications for the care of nursing. The research was focused on a qualitative nature, and was used to collect data: a semistructured and participant observation systematic. The social actors were the professionals in the nursing staff working in a public hospital in the state of Rio de Janeiro. The study was based on the ideas of Valadares (2006), which talks about the face of new knowledge. From the results, emerged three categories, being able to learn that: the teams of nursing (re) act in an unique way, depending on the location in which they work, the experience modifies the attitudes in this situation, and there are factors that influence the daily nursing care provided to the customers.
\end{abstract}

Keywords: Heart Arrest. Nursing care. Nursing team.

\section{Resumen}

Esta investigación mostró los siguientes objetivos: conocer la experiencia del personal de enfermería en el proceso de atención al cliente a través de detenerse en cardiopulmonar; relacionar esta situación del conocimiento teórico con el práctico; discutir las posibles implicaciones para el cuidado de enfermería. A la búsqueda de privilegios de carácter cualitativo, y se utilizó para recopilar datos: una entrevista semi-estructurada y sistemática de la observación participante. Los actores sociales son profesionales en el personal de enfermería que trabaja en un hospital público en el estado de Río de Janeiro. El estudio se basa en las ideas de Valadares (2006), que habla sobre la faz de nuevos conocimientos. De los resultados, surgieron tres categorías, y que puede aprovechar: la de los equipos de enfermería (re) actuar de manera singular, en función de la ubicación en la que trabajo, la experiencia modifica las actitudes en esta situación, y hay factores que influyen en el diario de enfermería la atención esta clientela.

Palabras clave: Paro cardíaco. Atención de enfermería. Grupo de enfermería; 


\section{CONSIDERAÇÕES INICIAIS}

Trata este estudo de um trabalho de conclusão de curso realizado por uma Acadêmica de Enfermagem do Curso de Graduação da Escola de Enfermagem Anna Nery (EEAN), da Universidade Federal do Rio de Janeiro (UFRJ), que, a partir da vivência na graduação, considerando os estágios curriculares supervisionados, passou por muitas situações inquietantes, especialmente, no que diz respeito à temática: o cuidado de enfermagem na parada cardiopulmonar.

Visto ser este um procedimento complexo, é importante salientar que: para uma efetiva reanimação cardiopulmonar, faz-se necessária uma equipe multidisciplinar competente que esteja ciente de qual é o seu dever no cuidado ao cliente. Essa equipe precisa ter a compreensão da importância dos cuidados ditos instrumentais, sem esquecer os cuidados expressivos, mesmo que, nesse momento, isso não se dê, de fato, regularmente, quando das assistências em unidades especializadas.

Como a parada cardíaca é um acontecimento marcado pela imprevisibilidade, podendo ocorrer a qualquer momento e em qualquer local, é necessário que os profissionais de saúde, e nesse bojo 0 enfermeiro, tenham um comportamento de busca em prol da educação permanente, a fim de obter e/ou reafirmar o conhecimento necessário para uma boa prática do cuidado, no que se refere à eficiência e à eficácia da assistência prestada.

De tal modo, partindo dos delineamentos acima, tem-se 0 problema deste estudo: como os profissionais de enfermagem (re)agem no atendimento à parada cardiopulmonar do cliente considerando o cuidado de enfermagem?

Em vista deste problema, algumas questões foram formuladas a fim de nor tear esta pesquisa, em que pese:

Como a equipe de enfermagem, no processo de trabalho, vivencia a estrutura do cuidado ao cliente em parada cardiopulmonar considerando atitudes e práticas?

Qual a articulação entre o conhecimento teórico e prático da equipe de enfermagem a partir do (re)agir diante da parada cardiopulmonar?

Quais as implicações da infra-estrutura para o cuidado de enfermagem a partir desse enfrentamento?

Com intuito de tornar o estudo exequível foram elaborados os seguintes objetivos:

Conhecer a vivência da equipe de enfermagem no processo do cuidado mediante o cliente em parada cardiopulmonar;

Relacionar nesta situação a interseção entre 0 conhecimento teórico e o conhecimento prático em diferentes cenários de prática.

\section{REFERENCIAL TEÓRICO-METODOLÓGICO}

0 estudo baseou-se nas idéias de Valadares ${ }^{1}$, que discorre sobre a formação do enfermeiro diante do enfrentamento do conhecimento novo em setores especializados. Apesar de a parada cardiopulmonar não ser um conhecimento novo e, por conseguinte, o enfermeiro ter alguma proximidade ou mesmo domínio do conhecimento, quando ocorre tal evento, torna-se algo inusitado, haja vista a idéia de tratar-se de um fenômeno marcado pela imprevisibilidade.

Dessa forma, à luz do referencial, para compreender os caminhos adotados pelo enfermeiro no âmbito de sua prática profissional, é preciso desvelar os significados presentes no seu mundo social, a despeito do que sentem, do que entendem, de como definem, de como agem e, obviamente, de como reagem, no dia-a-dia mediante 0 trabalho da enfermagem. Portanto, o significado do enfrentamento se constrói numa esfera singular, a partir da vivência de cada agente social.

Nessa perspectiva, torna-se um imenso desafio cuidar no âmbito de uma situação específica, sendo esse enfrentamento uma fase de várias descobertas e reveladoras experiências. Por um lado, a vivência dentro do que já se conhece reforça um agir independente, enquanto a vivência do desconhecido gera tensões e angústias, exigindo respostas em tempo hábil.

Essa circunstância aponta para um processo adaptativo marcado por fragilidades, posturas apreensivas, busca de ânimo interior e até mesmo comportamentos surpreendentes no enfrentamento dos dilemas instituídos, porém compromissados com 0 valor essencial da profissão, em que se destaque a realização do cuidado digno e com qualidade, em qualquer que seja a circunstância ${ }^{1}$.

No que se refere à abordagem metodológica, realizou-se um estudo de natureza qualitativa, haja vista que este tipo de pesquisa busca compreender as questões tidas como particulares. Assim, preocupa-se com um nível de realidade que não pode ser quantificado, ou seja, trabalha com o universo de significados, motivos, aspirações, crenças, valores e atitudes, o que corresponde a um espaço mais profundo das relações, dos processos e dos fenômenos. Esses não podem ser reduzidos à operacionalização de variáveis².

0 cenário escolhido para desenvolver o estudo foi um hospital estadual do Rio de Janeiro de médio porte, voltado para tratamentos de emergência, composto por dois andares. 0 setor de emergência, que se localiza no primeiro andar, se divide em clínica ortopédica, bucomaxilo, hipodermia, sala de trauma, grande emergência e emergência pediátrica. 0 segundo andar compreende as enfermarias de clínica cirúrgica, clínica médica e clínica or topédica, destinada a homens e mulheres adultos, enfermaria pediátrica, um centro cirúrgico e um centro de terapia intensiva para adultos.

Os atores sociais foram 9 profissionais da equipe de enfermagem, sendo 5 que trabalham na emergência (1 enfermeiro, 2 auxiliares de enfermagem e 2 técnicos de enfermagem), vivendo no cotidiano o procedimento de reanimação cardiopulmonar, e 4 que trabalham somente nas enfermarias do hospital ( 2 enfermeiros, 1 auxiliar de enfermagem e 1 técnico de enfermagem) e, por conseguinte, não vivenciam, freqüentemente, este tipo de atendimento.

No sentido de garantir sigilo dos depoentes, para identificação dos atores sociais, foram utilizadas as iniciais de seu local de trabalho. Portanto, aqueles que trabalham na enfermaria foram identificados como En e na emergência, como Em. Para a distinção, considerando a catego ria profissional, foi 
utilizada a seguinte numeração: 1 para os enfermeiros, 2 para técnicos de enfermagem e 3 para auxiliares de enfermagem.

Os instrumentos utilizados para a coleta de dados foram a entrevista semi-estruturada e a observação assistemática. As entrevistas foram realizadas nos postos de enfermagem das enfermarias e na sala destinada ao descanso da equipe de enfermagem da emergência do hospital. Estas foram gravadas em formato MP3 e transcritas na íntegra. Ainda, quanto à observação assistemática, esta foi utilizada por ser uma técnica na qual o pesquisador procura recolher e registrar os fatos da realidade sem a utilização de meios técnicos especiais, ou seja, de forma simples durante seu momento de prática ${ }^{3}$.

Cabe ressaltar que o estudo foi apresentado para análise no Comitê de Ética em Pesquisa (CEP) da Escola de enfermagem Anna Nery/Hospital São Francisco de Assis (EEAN/HESFA), bem como para o Centro de Estudos do próprio hospital e para Secretaria de Saúde do Estado do Rio de Janeiro. Também, 0 estudo atendeu a todos os aspectos da Resolução 196/96 sobre Pesquisa Envolvendo Seres Humanos.

Desta forma, foram observados os princípios éticos da pesquisa, como: 0 uso do termo de consentimento livre e esclarecido dos indivíduos informantes, proteção aos grupos vulneráveis e aos legalmente incapazes; ponderação entre risco e benefício, sigilo e anonimato, dentre outros aspectos, não perdendo 0 sentido de sua destinação, no que tange à justiça, à beneficência, à não-maleficência e à equidade.

Para analisar o conteúdo, foi utilizada a técnica que define a análise de conteúdo, visando obter, através de procedimentos sistemáticos e objetivos de descrição do conteúdo das mensagens, indicadores que permitissem a explicitação de inferências explicativas e conceituais, no que tange aos conhecimentos relativos às condições de produção/recepção destas mensagens ${ }^{4}$.

Os resultados foram tratados em um sistema categorial: origem, implicação, descrição e sentimentos. Portanto, os resultados foram inicialmente agrupados em categorias empíricas e, posteriormente, em categorias analíticas fundamentadas à luz do referencial teórico.

\section{RESULTADOS}

A análise surgiu a partir dos depoimentos das equipes de enfermagem da emergência, bem como das equipes que trabalham nas enfermarias, à luz do referencial teórico selecionado e de outros autores importantes vinculados ao procedimento de parada cardiopulmonar.

Emergiram, portanto, três categorias que foram denominadas da seguinte maneira: 1) diferenças marcantes em um só mundo; 2) relacionando o conhecimento teórico com o prático na parada cardiopulmonar; 3 ) enfrentando dificuldades associadas ao ambiente de trabalho, que foram elaboradas considerando-se os objetivos propostos para o estudo.

\section{Diferenças marcantes em um só mundo}

Esta categoria revelou como as equipes de enfermagem agem diferentemente, dependendo do local onde atuam, isto é, no pronto-socorro ou na enfermaria, pois a forma de organização marca o espaço do trabalho, e isso inclui 0 agir/ reagir mediante o cuidado de enfermagem. Portanto, as diferenças entre esses setores tanto acontecem no campo do espaço físico ou organização da unidade, como também sucedem no enfrentamento das equipes desses setores diante do evento de uma parada cardiopulmonar.

Buscando compreender esta temática, houve a necessidade de entender qual é a verdadeira missão do Hospital. Assim, percebemos que existem várias metas e em um mesmo hospital, porém sempre existirá um objetivo geral que rege a base desta instituição, a saber: salvar vidas e minorar o sofrimento humano $0^{6}$.

Um estabelecimento de saúde é, portanto, um lugar a que as pessoas que têm algum tipo de doença ou que necessitam de tratamento recorrem em busca de auxilio, para que seus problemas sejam resolvidos ou amenizados através da promoção, prevenção e reabilitação da saúde. ${ }^{7}$

Trata-se de um local onde se prestam serviços tais como: assistência médica hospitalar, hemoterapia, serviço laboratorial e ambulatorial, patologia clínica, pronto-atendimento, diagnóstico, atenção primária à saúde e assistência domiciliar, que diferem entre si. Porém, estes serviços estão interligados de tal forma que o funcionamento de um interfere no do outro; por isso, existe a necessidade da interação dos profissionais que compõem este mesmo mundo ${ }^{8}$.

Para facilitar 0 entendimento dessas diferenças entre setores, preliminarmente e, sucintamente, é importante salientar como é a dinâmica de trabalho desses setores. Sendo assim, cabe pontuar que a emergência destina-se à prestação de cuidados imediatos ao cliente. Para funcionar de forma eficaz, esta unidade necessita de uma equipe multidisciplinar capacitada para 0 atendimento de reanimação cardiopulmonar, que realize atividades de avaliação dos processos da unidade, bem como de equipamentos, medicamentos e materiais compatíveis com a estrutura de um serviço de emergência?.

Portanto, seguindo este raciocínio, a emergência deverá funcionar em local de uso exclusivo, com acesso independente, espaços separados para consultas e procedimentos, área de observação individualizada com fonte de oxigênio, ar comprimido e vácuo, além do apoio diagnóstico, terapêutico e acesso ao centro cirúrgico nas primeiras 24 horas?.

No que se refere à enfermaria, seguindo uma outra lógica, relaciona-se com a internação de clientes, que necessitam de uma assistência direta, pro-gramada ou não, por um período superior a 24 horas. Para tanto, é preciso ter instalações adequadas com condições de conforto e segurança que contribuam para a boa assistência do cliente ${ }^{9}$.

Para que esta assistência seja humanizada, de boa qualidade e que permita uma continuidade, a unidade dispõe de um responsável técnico habilitado para coordenar a equipe de profissionais, bem como um profissional médico responsável pela internação até a alta? 
Vale ressaltar que no contexto do serviço de enfermagem em emergência, as tensões estão continuamente presentes, exigindo atitude calma e reflexiva no planejamento de suas ações no momento de priorizar o que precisa ser feito, pois a todo instante surgem situações emergenciais que precisam ser atendidas em detrimento de qualquer outro evento que esteja sendo realizado, diferente das unidades de internação, que costumam permanecer com o planejamento similar de ação desde a admissão até a alta do cliente ${ }^{8}$.

Outro aspecto importante para a reflexão cabe ao próprio enfrentamento, já que no setor de emergência esse evento ocorre com maior freqüência e a equipe já se organiza cotidianamente, estando preparada para o advento de uma situação de parada durante um plantão. Entretanto, a equipe de uma unidade de internação não espera, necessariamente, que este acontecimento ocorra e, quando ele sobrevém, acaba acontecendo dentro de uma lógica diferenciada, haja vista a questão da imprevisibilidade, podendo desestruturar todo 0 planejamento, inclusive aquele pensado pela equipe de enfermagem. Este fato pode ser exemplificado na fala a seguir:

0 material já fica todo preparado, inclusive a medicação... 0 respirador já fica preparado, para, na hora de chegar a parada, já estar tudo no esquema. (En 3)

É possível perceber, através desta fala, que, na atuação de uma equipe na emergência, está implícito que o material para uma possível reanimação cardiopulmonar precisa estar preparado durante todo o plantão de 24 horas. Com isso, quando presente 0 advento da parada cardiopulmonar, a equipe não enfrentará problemas organizacionais. Já analisando os depoimentos das equipes das unidades de internação, 0 que se observa é uma significativa dificuldade relacionada aos recursos humanos, perceptível nas falas seguintes:

[...] geralmente quando tem uma parada vai o médico, nós contatamos o médico, e vão ele e duas auxiliares de enfermagem. É o suficiente. Quando tem enfermeiro, vão um enfermeiro, um auxiliar, ou duas auxiliares e o médico. Assiste-se o cliente de acordo com a orientação médica. 0 médico pede e nós executamos.(En 1).

... porque a minha equipe é uma equipe que está defasada, tem duas técnicas e uma auxiliar, então, quando ocorre 0 episódio de $P C R$, a equipe se distribui em duas ou três pessoas para agir. Mas, quando tem mais gente, geralmente na escala são cinco auxiliares, se estiverem os cinco auxiliares um fica no posto. E o posto nunca fica vazio. (En1)

Nota-se ainda nestes discursos que algumas pessoas que trabalham nas unidades de internação não conseguem ter uma organização de fato estabelecida para atuar na reanimação cardíaca. Percebe-se, também, que existe um pensamento de que para reverter o quadro de parada cardiopulmonar, é necessário garantir quantidade de funcionários. Entretanto, não existe uma explicitação mesma do que realmente é preciso saber/fazer junto ao cliente que vive a parada cardíaca.

\section{Relacionando o conhecimento teórico com o prático na parada cardiopulmonar}

Durante o estudo, foi possivel perceber que, dependendo da experiência que a pessoa tenha adquirido no decorrer de sua formação ou carreira profissional, essa terá maior preparo para 0 enfrentamento da situação estudada, haja vista a utilização de protocolos na assistência mediante a reanimação cardiopulmonar, mesmo que se precise passar por processos relacionados à educação permanente para manter-se atualizado.

Para destrincharmos esta categoria, portanto, é necessário entender que não é possível dissociar o fazer do pensar, ou seja, a prática da teoria, pois o fazer produz, executa, cria, torna, dentre outras possibilidades. 0 pensar nos leva a raciocinar, refletir e imaginar. ${ }^{10}$

Outro ponto importante que deve ser observado refere-se à idéia de que, na prática, o processo de enfermagem não é implementado na sua totalidade, ou seja, apenas algumas etapas são rotineiramente executadas, como exame físico e a prescrição de enfermagem, demonstrando, portanto, uma falta de referencial teórico no cotidiano das práticas cuidativas ${ }^{10}$.

Dentro do que foi exposto, pretendemos aqui mostrar que a recuperação do cliente não depende apenas de medicações e do tratamento médico pertinentes ao quadro clínico, mas também depende da assistência planejada por meio do processo de enfermagem, assim como da integração/interação da equipe multidisciplinar na busca da recuperação das condições de saúde do ser humano ${ }^{10}$.

Ainda a este ponto, cabe salientar que o cotidiano é permeado por situaç̧ões que sinalizam grandes dificuldades. De tal modo, é importante ressaltar, que a assistência ao ser humano enfrenta problemas quando da sua implementação em que pese a dissonância entre 0 conhecimento teórico e aquele que se emprega na prática. Além disso, também existe um excesso de demanda, ou seja, no que tange aos serviços propriamente ditos, o número de leitos e as inúmeras atividades emergentes no espaço do trabalho em saúde acabam transformando o processo de cuidar, nem sempre para melhor ${ }^{11}$.

Tantas mudanças drásticas, rápidas e globais, como se tem nos dias de hoje, deveriam impulsionar os profissionais pela busca do aprimoramento e da atualização, considerando os avanços exigidos nos diferentes aspectos de sua prática. Desse modo, o desafio é significativo, pois hoje é preciso saber utilizar toda uma aparelhagem sofisticada, ou seja, tecnologia de ponta, dotada de grande especificidade ${ }^{1}$.

Como não poderia deixar de ser pontuado, cabe especial atenção ao cuidado na parada cardiopulmonar, tendo em vista que, além da tecnologia, o profissional terá que avançar também no controle de si mesmo, deparando-se com um amadurecimento, a chamada inteligência emocional. 
Portanto, no âmbito de uma situação de parada cardiopulmonar, é exigido da equipe de enfermagem um amplo conhecimento teórico e prático, que precisa estar articulado com uma profundidade específica, para que ocorra uma atuação livre de danos, sem agravos idiopáticos. Observe a fala a seguir:

... enquanto uma está massageando, a outra já está ventilando, alguém já está aqui no posto solicitando um médico da emergência. A nossa caixa de parada, na medida do possível, a gente já deixa tudo organizado, e desse modo uma já está aspirando as medicações, que normalmente a gente vai utilizar. Quando o médico chega, o laringoscópio já está preparado, o tubo já está preparado. (En3)

Este ator social, por exemplo, além de trabalhar em uma enfermaria, também trabalha na emergência de um outro hospital. Logo, ao longo de sua carreira adquiriu experiência no processo de reanimação cardiopulmonar, tendo amadurecimento profissional para atuar caso ocorra este evento em uma unidade de internação.

Essa categoria vem demonstrando, portanto, que a experiência que a pessoa adquire no decorrer de sua formação ou carreira profissional, estando em contato direto com os cuidados de enfermagem, modifica o (re)agir mediante a PCR. Logo, o tempo de trabalho em um determinado setor leva a uma dada especialização na prática. Esta especialização aumenta a eficácia do trabalhador e a quantidade/qualidade do que é realizado por ele. ${ }^{1}$

\section{Enfrentando dificuldades associadas ao ambiente de trabalho}

Esta categoria mostra que existem diversos problemas em relação ao espaço físico utilizado para realização dos procedimentos de emergência, considerando os recursos materiais e humanos que influenciam na atuação da equipe de enfermagem em prestar uma assistência de qualidade aos clientes em parada cardiopulmonar.

Além disso, o enfermeiro presta assistência em setores considerados desgastantes, tanto pela carga de trabalho como pelas especificidades das tarefas, além de viver uma estreita relação com o processo de dor, morte, sofrimento, desespero, incompreensão, irritabilidade, tantos outros sentimentos e reações desencadeadas pelo processo doença.

Nesse contexto, encontram-se a unidade de pronto-socorro e os profissionais que lá atuam. Porém, apesar de existirem diversos fatores estressantes nesta profissão, pode-se considerar que a maior fonte de satisfação no trabalho do enfermeiro em uma unidade de emergência concentra-se no fato de que as suas intervenções auxiliam na manutenção da vida humana. ${ }^{12}$

Como principais estressores existentes nesta unidade, é possível citar: número reduzido de funcionários compondo a equipe de enfermagem; falta de respaldo institucional e profissional; carga de trabalho; necessidade de realização de tarefas em tempo reduzido; indefinição do papel do profissional; descontentamento com o trabalho; falta de experiência por parte dos supervisores; falta de comunicação e compreensão por parte da supervisão de serviço; relacionamento com familiares; ambiente físico da unidade; tecnologia de equipamentos e assistência ao cliente. ${ }^{12}$

Isto pode ser demonstrado através do seguinte depoimento:

\begin{abstract}
A dificuldade éo espaço, que é muito pequeno, em virtude de material regular, com deficiências de equipamento, mas a princípio é o espaço físico, porque você perde muito tempo em procurar um espaço, inclusive perto mesmo do cardioversor; deveria ter um local apropriado para você receber esse tipo de paciente, infelizmente dentro da unidade não tem.(Em2)
\end{abstract}

As equipes que exercem sua função na sala de emergência enfrentam diversas dificuldades acerca da falta de materiais, equipamentos, espaço físico, dentre outros aspectos. A partir daí, tudo passa a ser vivenciado de forma intensa e singular, com extremos de sentimentos e valores, atitudes e comportamentos, pensamentos e práticas, que podem variar desde os mais alegres e tranqüilizadores até aqueles marcados pela raiva e a revolta ${ }^{1}$.

Outro achado interessante no estudo foi em relação à experiência vivida no processo de formação, seja na graduação ou pós-graduação, e o fato de se deparar com uma outra realidade, totalmente diferente no local de trabalho, precisando se adaptar a esta nova realidade. Isto pode ser identificado na seguinte fala:

Você tem uma realidade quando se forma e uma segunda realidade quando você começa a trabalhar. Os hospitais do estado são extremamente carentes. Você tem pouca modernidade. Então, tem coisas que você aprende, mas não aplica aqui ...(En 1)

De acordo com o referencial teórico aqui utilizado, cabe a reflexão de que o contexto implica diretamente a vivência de muitas situações que lhe são desconhecidas, principalmente quando se encontram em um momento em que os seus próprios sentimentos permeiam a interpretação da situação ${ }^{1}$. Existe, portanto, uma apreensão no que se refere ao conhecimento exigido em dada realidade. Essa discrepância não significa uma desvalorização do profissional, mas uma conjuntura circunstancial que deixa 0 enfermeiro em choque, uma vez diante do inesperado, fazendo-o pensar e pensar, tentando encontrar algumas saídas para um encorajamento.

0 enfermeiro percebe que, nesta fase, apesar da pouca intimidade e da distância com os esquemas operacionais, aspectos positivos relacionados ao inesperado também emergem da representação de que tal experiência poderá ser conveniente para a sua carreira na enfermagem, acrescentando novas possibilidades ao seu conhecimento, estabelecido ao longo da sua trajetória profissional' ${ }^{1}$. 


\section{CONSIDERAÇÕES FINAIS}

Como procuramos demonstrar ao longo do trabalho, 0 procedimento de reanimação cardiopulmonar é um processo complexo que envolve diversos fatores. Entre eles encontramse a equipe de enfermagem e o seu enfrentamento. Este varia de acordo com o setor em que esta equipe atua, pois dependendo da unidade, o processo de parada cardiopulmonar pode se tornar um procedimento novo, nunca antes presenciado por esta equipe.

Entretanto, encontramos profissionais que no decorrer de sua formação ou carreira profissional adquiriram um grande conhecimento do cuidado ao cliente em parada cardiopulmonar. Esses profissionais, por já terem presenciado e atuado neste evento diversas vezes, em outros ambientes hospitalares, enfrentavam este procedimento sem grandes dificuldades.

Sendo assim, é possível articular nesta situação o conhecimento teórico e o conhecimento prático da equipe de enfermagem, já que 0 estudo reafirma em seus achados que não é possível dissociar o fazer do pensar, ou seja, a prática da teoria, pois o saber/fazer produz, executa, cria, torna, dentre outras possibilidades. 0 (re)agir reflexivo permite uma prática mais segura.

Além disso, ao longo do estudo, pôde-se conhecer a vivência da equipe de enfermagem no processo do cuidado do cliente

\section{Referências}

1.Valadares GV, Viana LO. A formação profissional e o enfrentamento do conhecimento novo: a experiência do enfermeiro em setores especializados. Rio de Janeiro (RJ): EEAN/ UFRJ; 2006.

2.Minayo MCS, organizadora. Pesquisa social: teoria, método e criatividade. Rio de Janeiro (RJ): Vozes; 1994.

3.Boni V, Quaresma S). Aprendendo a entrevistar: como fazer entrevistas em ciências. Rev Eletr Pós-Graduandos em Sociologia Política da UFSC 2005; 2 (1): 3.

4.Bardin A. Análise de conteúdo. São Paulo (SP): Martins Fontes; 1979.

5.Lüdke M. Pesquisa em educação: abordagens qualitativas. São Paulo (SP): EPU; 1986.

6.Cecilio LCO. Trabalhando a missão de um hospital como facilitador da mudança organizacional: limites e possibilidades. Cad Saude Publica 2000 out/dez; 16 (4). em parada cardiopulmonar, tanto no setor de emergência como na unidade de internação. As equipes desses setores, mesmo fazendo parte de uma única instituição, possuem maneiras diferenciadas de organização e planejamento para enfrentar este procedimento.

Discutindo sobre as implicações para o cuidado de enfermagem a partir desse empreendimento, percebemos que as equipes de enfermagem enfrentam diversos problemas em relação ao espaço físico utilizado para realização dos procedimentos de emergência. Além desses, ressaltam-se, ainda, os recursos materiais e humanos, que interferem diretamente na atuação da equipe, considerando a busca por uma assistência de qualidade aos clientes em parada cardiopulmonar.

De tal modo, cabe a ênfase em que a reanimação cardiopulmonar é um procedimento extremamente importante, do qual dependem o restabelecimento e a manutenção da vida do cliente. Portanto, seu atendimento independe de setor, experiência vivida na enfermagem ou problemas em relação à infra-estrutura da instituição de saúde. A equipe de enfermagem deve estar preparada para 0 enfrentamento dessa situação. Faz-se então, necessário, que os profissionais busquem aprimoramento através da educação permanente, bem como entenda o compromisso técnico, ético e social implícito quando da escolha profissional.

7.Guia do hospital-Tire suas dúvidas sobre hospital: dicas, formas de atendimento, tudo o que é interessante sobre os hospitais se encontra aqui. [citado 22 nov 2007]. Disponível em: http://www.hospitalbr.com.br/hospital/hospital.asp.

8.Lima SBS, Erdmann AL. A enfermagem no processo da acreditação hospitalar em um serviço de urgência e emergência. Acta Paul Enferm 2006; 19(3): 27: 1-8.

9. Novaes HM, coordenador. Manual Brasileiro de Acreditação Hospitalar. Brasília (DF): Ministério da Saúde/ Secretaria de Políticas de Saúde; 1998.

10.Kletemberg DF, Mantovani MF, Lacerda MR. Entre a teoria e as práticas do cuidar: que caminho trilhar? Cogitare Enferm 2004; 9(1). 11.Schneider DS, Pedroso M. Sistematização da assistência de enfermagem e influência no cotidiano. Logos 2006; 17 (1): 11-20.

12.Batista KM, Bianchi ERF. Estresse do enfermeiro em unidade de emergência. Rev Latino-am Enfermagem 2006 jul/ago; 14 (4). 